\title{
Medical Marijuana as a Therapeutic Treatment for Pediatric Oncology Patients
}

\author{
Lindsay G. Hunt ${ }^{1}$
}

\author{
${ }^{1}$ Department of Biomedical Sciences, Colorado State University, Fort Collins, CO
}

\begin{abstract}
In the United States, many children face the life threatening reality of cancer. As the second leading cause of death of children, 1,250 people younger than 15 years old are expected to die from cancer in 2015 alone ${ }^{1}$. Each year, pediatric cancer diagnoses make up less than $1 \%$ of all cancers diagnosed; regardless, 10, 380 children in the US will be diagnosed in $2015^{1}$. Childhood cancers are generally not associated with environmental or lifestyle factors like some adult cancers. Instead, they are most commonly attributed to DNA mutations. Leukemia, central nervous system tumors, neuroblastoma, Wilms tumor, lymphoma, rhabdomyosarcoma, retinoblastoma and bone cancers are the most common childhood cancers ${ }^{2}$. In adolescence, Hodgkin lymphoma, thyroid carcinoma, brain and central nervous system tumors and testicular germ cell tumors are the most common ${ }^{2}$. Thankfully, medicine and oncology research continues to expand, improving the survival rate of the youngest victims. Survival forecasts predict that an average $80 \%$ of children with cancer will survive at least 5 years ${ }^{1}$. However, with these vulnerable patients, questions and gaps in knowledge still remain. How can doctors treat these unpleasant symptoms effectively and with the fewest rate of negative consequences? With medical marijuana gaining popularity legality in several states, physicians and scientists are faced with the question: should medical marijuana be prescribed as a palliative or therapeutic treatment for pediatric oncology patients?
\end{abstract}

\section{Introduction}

The $21^{\text {st }}$ century is not the first time marijuana has appeared medicine. Ancient cultures hailed marijuana as a common herbal medicine useful for treating a variety of illnesses. Chinese Emperor Shen Nung in 2700 B.C. explored the healing properties of marijuana to treat rheumatism, malaria, and absentmindedness, while later healers explored the treatment of vomiting, parasitic infections, hemorrhage, diarrhea and dysentery ${ }^{3}$. In India, Ayurveda medicine implemented marijuana to increase sleep, appetite and digestion, and relieve pain ${ }^{3}$. In ancient Greece and Rome, Galen and Pliny the Elder prescribed it for a variety of conditions including earaches ${ }^{3}$. In the 1830 s, an Irish physician concluded from his experiments on animals and humans that marijuana was an effective treatment for vomiting, diarrhea and cholera ${ }^{4}$. Later in 1860 , the first conference discussing marijuana as a treatment for chronic coughs, gonorrhea and chronic pain was held at the Ohio State Medical Society ${ }^{5}$. With this increased medical interest in marijuana, companies such as Grimault and Co. sold marijuana cigarettes for asthma treatment ${ }^{5}$. Today, however, the majority of Americans advocate the plant for its recreation use. In January of 2014, marijuana was defined by the National Institute on Drug Abuse as the most widely used illicit drug in the US ${ }^{6}$.

In marijuana, cannabinoids compose the main active chemicals in marijuana responsible for the healing and "high" effects. The cannabinoids, the most common being delta-9-THC, originate in the resin glands of female plant leaves 5. Kari Fransom, PharmD. Ph.D., at the University Of Colorado Skaggs School Of Pharmacy concludes that, "Depending on the strain, THC content can vary from $2 \%$ or $3 \%$ to more than $20 \%$ " 7 . Which part of the plant is processed and how the plant's contents enter the body affects the overall effect of THC on the physiology of the body. If taken orally, the THC compounds first travel to the liver and then enter the circulatory system causing a slower peak of THC concentration resulting in a slower effects and a higher potential for abuse. However, when the compound is smoked, the contents enter the blood stream almost immediately traveling to the CNS which results in a more "pleasurable" experience and rapid peak THC concentrations ${ }^{8}$. The metabolized 11-OH-9-THC from the liver is a weaker antiemetic and results in a stronger psychological effect than THC entering the lungs ${ }^{9}$. Peak plasma concentrations of THC occur 1 to 6 hours after orally taken as

This article is published under the terms of the Creative Commons Attribution License 4.0

Author(s) retain the copyright of this article. Publication rights with Alkhaer Publications.

Published at: http://www.ijsciences.com/pub/issue/2015-11/

DOI: 10.18483/ijSci.860; Online ISSN: 2305-3925; Print ISSN: 2410-4477 
compared to inhalation which takes 2 to 10 minutes $^{8}$. Once in the circulatory system, cannabinoids bind to receptors on specific cells. Cannabinoids bind to cannabinoid receptors $(\mathrm{CB})$ in the cells of the brain and in the immune system: $\mathrm{CB} 1$ located in the brain slows reaction time and $\mathrm{CB} 2$ present on white blood cells impedes infection response and reduces inflammation ${ }^{5}$. The binding of THC-9 to the CB1 ligand reduces pain to the benefit of recreational users ${ }^{10}$. On the other hand, binding of THC-9 to CB2 works along with $\mathrm{CB} 1$ to maximize analgesia ${ }^{10}$. The isomer of $\Delta$-THC- $9, \Delta$-THC-8 has been investigated to have no significant side effects and is a possible pediatric antiemetic ${ }^{9}$.

The Controlled Substances Act of 1970 established that all drugs with a strong potential for abuse must be classified and regulated according to their medicinal value- drugs such as heroin and LSD are classified as schedule $1^{11}$. Schedule 1 substances, including marijuana, have "a high potential for abuse...have no currently accepted medical use in treatment..." 5 . In the early 1990s, surveys regarding drug addictions found that 1 in 10 people who tried marijuana became addicted as compared to 1 in 5 for heroin ${ }^{7}$. Despite its strict classification, marijuana can be legal to treat medical conditions including glaucoma, HIV/AIDS, muscle spasms, seizures, severe pain, severe nausea, cachexia, muscle atrophy and cancer; however, regulations vary from state to state $^{12}$.

In assessing the validity of medical marijuana for oncology palliative treatment, gaps in research and knowledge severely limit current knowledge. Most of the research surrounding medical marijuana's effect on the body comes from case studies; however, these case studies are limited because of the lack of biological or external validation ${ }^{13}$. Very few studies have compared marijuana and the current standards in antiemetic treatment. Also, the variability of THC concentration in each cannabinoid treatment causes analysis to be more nuanced and dose-dependent 5 . Marijuana's chemical complexity leads to complex responses in each individual that makes the compound difficult to regulate publically. Some researchers describe marijuana as "...a nonmedical, nonspecific, and potentially hazardous method of drug delivery" because marijuana contains so many active chemicals that have not yet been investigated 14. The American Medical Association has stated that "cannabis is a dangerous drug and as such is a public health concern" ${ }^{15}$. Despite these gaps in knowledge, some case studies and clinical evidence indicates the positive and negative effects of cannabis on the human body.

\section{Discussion}

Evidence in support of medical marijuana largely stems from patient and health care provider testimony. For example, in Cannabis in Medical Practice, Mary Lynn Mathre, R.N. states that "The cannabis plant (marijuana) . . . [has] therapeutic benefits and could ease the suffering of millions of persons with various illnesses such as AIDS, cancer, glaucoma, multiple sclerosis, spinal cord injuries, seizure disorders, chronic pain, and other maladies" 3 . In case studies, slowing of weight loss and increased appetite occurred in patients who took THC in the form of dronabinol ${ }^{5}$. Researchers have also observed that marijuana is effective for "...quelling nausea, suppressing vomiting, increasing appetite, relieving pain, and soothing anxiety....[and] the apparent advantage of treating several symptoms simultaneously." 5 . In a patient testimony, the man found that "when I smoked marijuana . . . in a couple of minutes...the symptoms of nausea would go away." 5 . In the New England Journal of Medicine, a physician survey about a 68-year-old diagnosed with metastatic breast cancer found that $76 \%$ of surveyed physicians agreed that they would prescribe medical marijuana for this patient's condition ${ }^{16}$. A physician commented that "that physicians who prescribe medicinal marijuana should do so only when conservative options have failed for fully informed patients treated in ongoing therapeutic relationships" 14. In one clinical trial of medical marijuana, the inhalation of medical marijuana resulted in a superior antiemetic effect ${ }^{17}$. In a comparative study of orally administered marijuana and prochlorperazine (Compazine), another antiemetic drug, marijuana performed significantly better to decrease nausea and vomiting in patients when the patients recognized marijuana as their antiemetic drug ${ }^{18}$. Medical marijuana as compared to other smoking habits has not officially be correlated to cancers of the respiratory system ${ }^{19}$. Relatively speaking, the dose needed to relieve symptoms such as nausea amounts to significantly less than the amount needed to make the person feel "high" 5.

On the other side of the argument, marijuana opponents defend the compound as hazardous and dangerous. Marijuana's interaction with molecular receptors in the body negatively affects physiological function by compromising complex thought and brain function. The CB1 receptors are present in the structures of the central nervous system responsible for movement, memory, stress and complex thought including the brain stem, spinal cord, cerebellum, hypothalamus and hippocampus ${ }^{5}$. Through positron emission tomography, scientists measured a decreased blood flow to the temporal lobe after smoking just one cigarette, coinciding with decreased auditory abilities with patients ${ }^{5}$. In a study of experienced airplane pilots under the influence of marijuana, even though the pilots stated themselves that their ability to fly would not be impaired, their overall performance on the simulator tests indicated significant impairment ${ }^{20}$. In clinical cases, 
"marijuana psychosis" characterizes a latent psychopathology including marijuana- induced states of schizophrenia, depression and mania ${ }^{21}$. Smoking marijuana can affect the cardiovascular and respiratory systems increasing the risk of heart attack and respiratory cancers. Acute THC effects include decreased ability of the vagus nerve to vary the heart rate in a changing environment causing an impaired "flight or fight" response and increasing risk of heart attacks ${ }^{7}$. Studies indicate that the risk of heart attack will increase by up to 4.8 times in the first hour after smoking marijuana ${ }^{22}$.

Respiratory injury, cancer, emphysema, heart disease, pregnancy complications and low birth weight are contributed to smoking, no matter the compound smoked ${ }^{5}$. Marijuana especially increases these risks when inhaled because marijuana smoker is held in longer than cigarettes 5. Polycyclic aromatic hydrocarbons (PAHs) exists as carcinogens when catalyzed by enzymes in the lungs and these enzymes are often readily available in marijuana smoker's lungs 5 . In addition to impairing cardiovascular and respiratory function, THC impairs the resting immune system function. When marijuana is bound to $\mathrm{CB} 2$ receptors on white blood cells, the white blood cells have a reduced capacity to proliferate and the $\mathrm{CB} 2$ receptor also impairs $\mathrm{T}$ and $\mathrm{B}$ cell activity which is responsible for immune response ${ }^{21}$.

For pediatric oncology patients, marijuana has a greater effect psychologically and behaviorally than it would on the more mature adult brain. In a longitudinal study for marijuana users under the age of 20 years, brain function decreased gradually by up to 6 IQ points ${ }^{7}$. Cognitive decline and poor attention and memory are linked to marijuana use in teen brain 13. Persistent young users of marijuana have a greater global neuropsychological decline than their adult counterparts ${ }^{13}$. This decline impacted the individual's ability to function in normal cognitive functions ${ }^{13}$. These negative effects of cannabinoids on the brain are attributed to physiological changes within the brain. Young brains have increased vulnerability to toxic insult because of neuronal maturation, neurotransmitter system maturation and rearrangement processes occurring in pediatric brains 23. Also, adolescents are more vulnerable to drug dependence because they more susceptible to behavior consequences even with lower doses of the drug 5. As compared to adults, children and adolescents experience more predominant mood change side effects from the minor compounds contained in cannabis ${ }^{9}$.

Some health professionals' observations of medical marijuana highlight the negative side effects of the treatment. Alen Budney, PhD, of Dartmouth College states that "THC can increase risk of acute and future problems with depression, anxiety and psychosis" 24 .
As a general rule, physician's state that symptoms such as panic, depress, depersonalization, delusions, illusions and hallucinations disappear within hours and "respond well to reassurance and a supportive environment" 5. According to Krista Lisdahl, PhD, "regular cannabis use, which we consider once a week, is not safe and may result in addiction and neurocognitive damage, especially in youth" ${ }^{24}$. In patients with impaired immune systems, researchers note that "smoking marijuana is likely to do more harm than good" 5 . Not to mention, marijuana has not been sufficiently compared to the current standards in antiemetic treatment. In comparison with Ondansetron (Zofran), a current emesis standard, marijuana afforded minimal antiemetic effects in comparison ${ }^{25}$. Is this palliative or therapeutic treatment worth these risks?

\section{Conclusions}

From testimonial observations, medical marijuana has been observed to ease the suffering of cancer patients by increasing appetite and decreasing nausea. On the other hand, medical marijuana has been proven to compromise physiological processes such as brain function, heart rhythm as well as creating a high potential for cancer-causing toxins. In view of these opposing viewpoints, the implementation of medical marijuana as a therapeutic treatment for pediatric oncology patients should not be encouraged until more scientific evidence reveals the benefits and detriments of medical marijuana on the younger population. Medical marijuana does afford antiemetic effect, which should be explored and investigated to its full potential. However, due to the serious negative effects of the marijuana on the nervous system, immune system and cardiovascular system for young patients, marijuana should not be implemented as a therapeutic particularly if it is in the form of smoking. Until more research can definitively state that marijuana will not significantly decrease brain function in young people, this medicinal treatment is not safe for a pediatric patient. Also, once marijuana is proven to supersede the current standards for emesis treatment, it should be implemented, but since very few studies have compared these options, marijuana is currently not a comparable antiemetic treatment. As observed by Bernard Lown M.D., "Caring without science is wellintentioned kindness, but not medicine." ${ }^{26}$. Medical marijuana may be helpful in caring for the patient temporarily, but it will not afford lasting beneficial treatment capable of medicine.

\section{References}

American Cancer Society. Cancer Facts \& Figures 2015 Atlanta: American Cancer Society; 2015.

Ward E, DeSantis C, Robbins A, Kohler B, Jemal A Childhood and adolescent cancer statistics. CA. 2014, Jan, 31. 64 (2): 83-103.

Mathre ML. History of Therapeutic Cannabis. Cannabis in medical practice: a legal, historical, and pharmacological overview of the therapeutic use of marijuana. Jefferson, 
North Carolina: McFarland \& Co.; 1997. p. 35-55.

4 O'Shaughnessy W. On the Preparations of the Indian Hemp or Gunjah. Provincial Medical Journal. 1843;5 (123):363-9.

$5 \quad$ Mack A, Joy J. Marijuana as Medicine? The Science Beyond the Controversy. Washington (DC): National Academies Press (US); 2000. Available from: http://www.ncbi.nlm.nih.gov/books/NBK224395/

6 Results for the 2013 National Survey on Drug Use and Health Summary of National Findings [Internet]. Substance Abuse and Mental Health Services Administration Center for Behavioral Health Statistics and Quality. U.S. Department of Health and Human Services; 2014 [cited 2015]. Retrieved from:

http://www.samhsa.gov/data/sites/default/files/nsduhresultsp dfwhtml2013/web/nsduhresults2013.pdf

7 Nelson B. Cannabis conundrum: Evidence of harm?: Opposition to marijuana use is often rooted in arguments about the drug's harm to children and adults, but the scientific evidence is seldom clear-cut. Cancer Cytopathology. 2015 Jan $14 ; 123(1)$ : 1-2.

8 Huestis M. Human Cannabinoid Pharmacokinetics. Chemistry and Biodiversity. 2009;4(8):1770-804.

9 Abrahamov A, Abrahamov A, Mechoulam R. An efficient new cannabinoid antiemetic in pediatric oncology. Life Sci. 1995; 56 (23-24):2097-102.

10 Izzo A, Sharkey K. Cannabinoids and the gut: New developments and emerging concepts. Pharmacology \& Therapeutics. 2010;126(1):21-38.

11 Controlled Substances Act. U.S. Food and Drug Administration. U.S. Department of Health and Human Services; 2006.

12 Hansen K. State Medical Marijuana Laws [Internet]. National Conference of state Legislatures; 2015 [cited 2015]. Retrieved from: http://www.ncsl.org/research/health/statemedical-marijuana-laws.aspx

13 Meier M, Caspi A, Ambler A, Harrington H, Houts R, Keefe R, McDonald K, Ward A, Poulton R, Moffitt T. Persistent cannabis users show neuropsychological decline from childhood to midlife. PNAS. 2012 Oct 2; 109(40): E2657E2664.

14 Bostwick J, Reisfiled G, DuPont R. Medicinal Use of Marijuana. NEJM. 2013 Feb 28. 368 (9):866-868.

15 Nelson S. AMA Reaffirms Opposition to Marijuana Legalization. US News and World Report. 2013;

16 Adler J, Colbert J. Medicinal Use of Marijuana- Polling Results. NEJM. 2013 May 29. 368(22); E30.

17 Chang A, Shiling D, Stillman R, Goldberg N, Seipp C, Rosenberg S, et al. Delta-9-Tetrahydrocannabinol as an Antiemetic in Cancer Patients Receiving High-Dose Methotrexate. Annals of Internal Medicine. 1979 Dec; 91(6): 816-824

18 Ungerleider J, Andrysiak T, Fairbanks L, Goodnight J, Sarna G, Jamison K. Cannabis and Cancer Chemotherapy. Cancer. 1982 Aug 15; 50(4) 636-45.

19 Pletcher M, Vittinghoff E, Kalhan R, Richman J, Safford M, Sidney S, Feng L, Kertesz S. Association Between marijuana Exposure and Pulmonary Function over 20 years. JAMA. 2012 Nov 11; 307(2):173-81.

20 Yeasavage J, Leirer V, Denari M, Hollister L. Carry-over effects of marijuana intoxication on aircraft pilot performance: A preliminary report. AJP. 1985 Nov; 142 (11):1325-1329.

21 Joy J, Watson S, Benson J. Marijuana and Medicine Assessing the Science Base. Washington DC: The National Academies Press, 1999.

22 Mittleman MA, Lewis RA, Maclure M, et al. Triggering myocardial infarction by marijuana. Circulation 2001;103(23):2805-9. Hashibe M, Morgenstern H, Cui Y, et al. Marijuana use and the risk of lung and upper aerodigestive tract cancers: Results of a population-based case-control study. Cancer Epidemiol Biomarkers Prev 2006;15(10):182934.

23 Jager G, Ramsey NF (2008) Long-term consequences of adolescent cannabis exposure on the development of cognition, brain structure and function: An overview of animal and human research.Curr Drug Abuse Rev 1:114 123.

24 Regular Marijuana Use Bad for Teens' Brains [Internet]. Washington DC: American Psychological Association; 2014 Aug 9.[cited 2015 May 5]. Available from: http://www.apa.org/news/press/releases/2014/08/regularmarijuana.aspx

25 Soderpalm A, Schuster A, de Wit H. Antiemetic efficacy of smoked marijuana: Subjective and behavioral effects on nausea induced by syrup of ipecac. Pharmacology of Biochemistry and Behavior [Internet]. 2001 [cited 2015];69(3-4):343-50. Retrieved from: http://www.sciencedirect.com/science/article/pii/s009130570 1005330

26 Lown B. The lost art of healing: practicing compassion in medicine. Boston: Houghton Mifflin, 1996. 